\title{
Low Velocity Impact Response of Carbon Fibre Laminates fabricated by Pulsed Infusion: A Review of Damage Investigation and Semi Empirical Models Validation
}

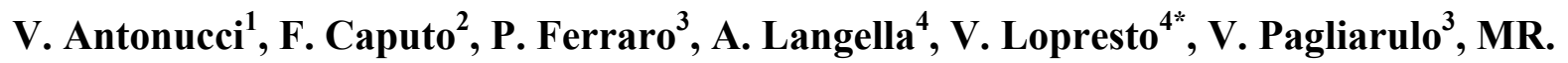

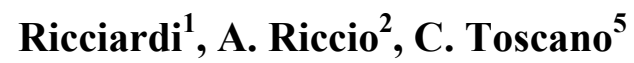 \\ ${ }^{1}$ CNR Research National Council, IMCB, Inst. of Comp. and Biom. Mat., P.E. Fermi, Portici (NA), Italy. \\ ${ }^{2}$ Dpt. of Aerospace and Mechanical Engineering, Second University of Naples, via Roma, 29, Aversa (CE), Italy. \\ ${ }^{3}$ CNR Research National Council, ISASI, Inst. of App. Sci. and Int. Sys., via Campi Flegrei 3480078 Pozzuoli (NA), \\ Italy. \\ ${ }^{4}$ Dpt. of Chemicals, Materials and Production Engin., University of Naples Federico II, P.le Tecchio, 80, Naples, Italy. \\ ${ }^{5}$ CIRA Italian Aerospace Research Centre, Via Maiorise sn, 81043 Capua (CE) Italy \\ * Corresponding author: Tel. +390817682216; e-mail: lopresto@unina.it
}

Keywords: low velocity impacts; composites; delamination; pulsed infusion; holography; thermography.

Summary: The research reported in this paper was aimed mainly to investigate the different NDE techniques on specimens made by a new process labelled as "pulsed infusion", very crucial for voids content under critical loading conditions. The impact load, in fact, is critical for composite laminates due to their anisotropy, in particular in extreme temperature conditions due to their brittleness. An additional and very relevant aim was to collect a large number of experimental results to supply useful information for the numerical models needed to simulate the dynamic behavior of composite laminates. At the aim to investigate the response under dynamic loads of laminates fabricated by a new vacuum assisted technology labelled as "pulsed infusion", rectangular carbon fibre composite specimens were subjected to low velocity impact tests. Experimental tests up to complete penetration and at different energy levels, were carried out by a modular falling weight tower. All the parameters related to the phenomenon, like penetration energy, maximum force and indentation depths, were used to validate existing semi empirical and numerical models. The largely used ultra sound technique (US) was adopted to investigate the delamination together with the thermo graphic technique. The results of the measurements were 
compared with data obtained on the same specimens by holographic analysis (ESPI). One of the scope was to investigate the crucial internal impact damage and assess the ability of an unconventional ND system (ESPI) in giving right information about non visual damage generated inside composite laminates subjected to dynamic loads. Moreover, some of the specimens were cut to allow the fractographic analysis. The efficiency of the above mentioned new fabrication technology was studied also comparing the results with measurements from literature on impacted autoclave cured laminates. By the comparison between the results, good agreements were found denoting the efficiency and the applicability of the new fabrication and the used NDE methods.

\section{Introduction}

Composites materials under dynamic loads, due to their non-homogeneous and anisotropic nature, can fail in a wide variety of modes. As a consequence, the integrity of the structural components can severely be reduced even if the visual damage is not so evident.

The different impact damages can be collected in: a) external damages like indentations, the plastic deformations left by the indenter on the surface and b) internal damages, like inter-laminar fractures (delamination) caused by inter-laminar stresses, fibres cracks (in-tension fibre breakage and in-compression fibre buckling) and matrix cracks. Moreover, the interaction between failure modes is very complex and assumes a primary role in understanding damage initiation and propagation $[1,2,3]$. A lot of efforts were done for many years $[1,2,3,4]$ at the aim to investigate about the influence of the large number of parameters involved in dynamic phenomena on the different modes of failure and the very complex response of composites to impact. A large number of experimental tests were carried out and the results widely studied but a lot of questions remain unanswered yet. Moreover, since the influence of a variety of parameters on the complex interaction between the failure modes, the latter can be hardly predicted by analytical and numerical tools $[5,6$, 7]. The same holds for residual compression strength after impact. 
Above all, another very critical aspect in this field is represented by the fabrication methods that are always or too expensive or too simple, meaning that the latter are often unable to obtain very good quality laminates. Moreover, since the most important problem is represented by the fact that the impact damage is not always a visible damage, the techniques, in particular the non destructive ones, to observe, measure and analyse the failures are continuously under attention.

Validated semi empirical models could be, however, an essential tool to reduce testing time and costs in the development phase, in particular way for impact tests on large structures which are becoming too expensive to be carried out in the development stage.

In this work, a large experimental campaign of low velocity impact tests has been carried out on composite laminates with the aim to supply useful information to develop an impact oriented design methodology. The laminates made by carbon fibres in polymeric matrix RTM6 have been manufactured by a new vacuum-assisted technology called Pulsed Infusion. Impact tests at complete penetration were carried out to obtain the complete load displacement curve allowing the penetration energy measurement. On the curve, different energy values were obtained in correspondence of load drops or changing in slope for the indentation tests. The indentation depths, measured by a confocal microscope, and the penetration energies were used to validate existing semi empirical models for the prediction of the impact energy and the residual strength. The data were analysed and used to validate existing semi empirical models for the prediction of the indentation depth left by the indenter on the surface of the specimen and of the internal damaged area. The agreement was quite good denoting the efficiency of the new used techniques.

The ultra sound technique (US) was adopted to investigate the delamination extension after low velocity impact tests. The results were compared with data obtained by thermo graphic and holographic analysis on the same specimens. The scope was to investigate the ability of different systems in giving right information about non visual impact damage, ability that was confirmed also by the comparison with numerical results and with measurements by destructive investigations. In 
the present paper, the efficiency of the new fabrication technology adopted was verified also by comparing the results with data from literature on impacted autoclave cured laminates.

In the present paper, some glass fibre laminates were recalled from literature to compare the data obtained on CFRP ones at the aim to validate the presented models. On these laminates, additional impact tests have been carried out at three different temperatures, room, $\mathrm{T}=-25^{\circ} \mathrm{C}, \mathrm{T}=-50^{\circ} \mathrm{C}$. The aim was to investigate the impact behaviour in extreme conditions of composites applied in naval field for the prediction of the response of these materials subjected to dynamic shocks, at the important aim to help the navigation in the Artic Ocean in safety conditions.

\section{Materials and experimental set up}

The composite laminates studied in the present work have been manufactured by a new vacuum assisted technology called pulsed infusion (Fig. 1). It is a double-bag technique based on the use of a proper designed pressure distributor, that allows to control the pressure of the vacuum bag on the dry fiber reinforcement and induces a pulsed transverse action to promote the through the thickness resin flow. Moreover, thanks to absence of the distributing net between the bagging film and the fibre reinforcement and to the use of this reusable pressure distributor, it is characterized by a reduction of material costs and a significant waste decrease [8].

Unidirectional layers of dry carbon fibres were overlapped following the stacking sequence $[(0) /(90) /(+45) /(-45)]_{\mathrm{s}}$, and immersed in a polymeric matrix of aeronautical use, RTM6, resulting in a laminate nominal thicknesses of $2.5 \mathrm{~mm}$.

The experimental tests have been carried out on a Ceast Fractovis drop weight tower: it is possible to vary the impact energy by changing the impactor mass and the drop height. Impact tests were, first, carried out up to the complete penetration of the coupons. The instrumented impactor had a cylindrical steel body with an hemispherical steel nose $19.8 \mathrm{~mm}$ in diameter. The rectangular specimens, 100x150mm, were clamped using a clamping device suggested by the EN6038 standard. 
The force-time and force-displacement curves obtained by the complete penetration tests were acquired by the DAS16000 acquisition program and successively studied for the calculation of the penetration energy and the variable energy values necessary for the indentation tests. The latter allowed the study of the evolution of the damage in terms of start and propagation. The variable energies of $6 \mathrm{~J}, 10 \mathrm{~J}$ and $13 \mathrm{~J}$, were measured in correspondence of characteristic points of the load curves, like load drops or changing in slope, clearly evidencing a changing in material behaviour like it is possible to observe in correspondence of a damage. The impact velocity was $1,8 \mathrm{~m} / \mathrm{s}$, $2,3 \mathrm{~m} / \mathrm{s}$ and $2.7 \mathrm{~m} / \mathrm{s}$ respectively and the minimum impactor mass of $3.6 \mathrm{~kg}$ was used for the tests. The different energy levels were obtained by varying the height of drop. Three tests were performed for each conditions.

The load curves recorded in all the test conditions were used to evaluate the main impact parameters involved in the phenomenon like penetration energies and maximum forces, as well as the correspondent displacements. Penetration and absorbed energy, first failure and maximum force have been measured.

The indentation depth was measured on each loaded specimen by a confocal microscope LEICA DCM3D (Fig. 2). Thanks to this advanced equipment it is possible to extract and record the threedimensional shape of the surface and the depth of the plastic deformation left by the impactor on the surface of the specimen. The dedicated software allows to measure the indentations and to obtain the shape and the roughness values as indicated by the international standards (ISO 4287). Moreover, thanks to this system, the acquisition and the management of the data is possible too.

From the acquired three-dimensional images, it is possible to extract the section in correspondence of which derive the information about the profile and, in the case of the impacted specimens, the measurement of the indentation left by the indenter. The software allows, then, to cut the chosen section and to measure the entities of interest, the indentation, I, with a maximum precision and in all the desired points of the surface. It allows also to manage the data. 
The DCM3D microscope is equipped with different magnifications (from $5 \mathrm{x}$ up to $150 \mathrm{x}$ ), with an $x-y$ table. In Fig. 3, an example of the surface recorded after an impact, is reported: the indentation is simply visible (dark blue area) and the high precision of the surface reconstruction is evident.

Olympus OmniScan ${ }^{\circledR}$ SX Phased Array Probe, 5 MHz Linear Array, automated data acquisition system by means of the a16:64PR phased array unit was used to non destructively investigate the internal damage [9]. The Pulse Echo technique has been adopted: the emitting probe captures the echo signals (first echo, back-wall echo and defect echo) to identify the damage into the specimen. Contact sound testing has been performed and the transducer is coupled to the material through a layer of water.

The C-scan inspection was adopted to obtain a plane view of the specimen. The plane of the image is parallel to the scan pattern of the transducer and allows to visualize and measure the eventual in plane damage like the delamination.

The software controls and analyses the probe providing a total plane image of the impact induced damage. The acquisition system is calibrated using an undamaged sample represented by uniform gray areas, while the damaged areas are usually represented by different shades of gray (in Fig. 4 an example of the virgin (a) and damaged (b) image was reported): the damaged area is easily identified and measured.

The impact damage produced on and inside the laminates was analysed via NDT (Non Destructive Testing) by using Lock-In Thermography [10 - 13]. Typical flaws revealed by the method are inclusions, porosity, delaminations, disrupted fibres, and inhomogeneous fibre/resin ratio. By choosing the proper stimulation light frequency it is possible to probe deeper into the structure, and to achieve information about its inner composition.

The used set-up is made up of an infrared camera SC5000 MW InSb by FLIR ${ }^{\circledR}$, four 1KW halogen lamps and their related driving system, and a pc with a dedicated software for data acquisition and data processing. In Figs. 5 and 6 the scheme of the set up and a photo of the lighting 
system and the camera were respectively reported. The light of the lamps is sinusoidally modulated to induce a thermal wave propagating within the material. The signal re-emitted by the material is captured by the thermal camera and processed by the software AltairI, which provides a phase map. The latter is a false colour picture in which a so called "phase" is associated to each point; actually this is the phase delay existing between the incoming signal and the signal re-emitted by the material. It depends on the thermal diffusivity of the material and on the frequency of the modulated light. It strictly depends on the thermal properties of the material. In the case of discontinuities in the material, the thermal properties are there locally different, and, as a consequence, the produced phase delay is locally different. This allows the defects detection though the phase maps. It is very common to use a metallic benchmark on the rear side of the inspected coupon in order to be sure that all the thickness is inspected. In the present case of this work a coin was used.

In Fig. 7, examples of some thermal phase maps obtained with a lighting frequency of $0.05 \mathrm{~Hz}$ on the front side, are shown. Each group of coupons were inspected on both front and back side. On the high side of the coupon impacted by $13 \mathrm{~J}$, the halo of the benchmark located on the rear side (coin) was indicated by the blue arrow. The impact areas are highlighted by the red arrows.

In the following images in Fig. 8, the phase maps of the rear sides are reported: they were obtained with a frequency of $0.075 \mathrm{~Hz}$ and in the central coupon the halo of the benchmark on the rear side (coin) can be noticed thanks to the blue arrow. Also here, the impact areas are highlighted by the red arrows.

The internal damages were evaluated also by an optical technique: the Electronic Speckle Pattern Interferometry (ESPI). It allows the measurement of displacements, strains and cracks on rough surfaces with high sensitivity [14 - 17], in real time. and in different points simultaneously, without any direct contact. It belongs to the family of coherent light interferometry techniques that include also holographic interferometry, speckle interferometry and speckle shearography. The measurement range and accuracy is related to the wavelength of the visible laser (i.e. wavelength $532 \mathrm{~mm}$ ). A CCD camera records the deformation under fringe form due to the heating of the 
material through the difference between a laser wavefront reflected (changed) and coming from the reference beam (unchanged). The deformations are recorded by whole-field differential displacement of surface field.

A typical scheme of the system for recording speckle interferometry measurements is illustrated in Fig. 9 [17].

The laser beam is divided into a reference beam and an object beam by means of a beam splitter, which enables control of the relation between reference and object. A speckled image of the object surface (result of the interference between the wavefronts of the two beams) is recorded through a CCD camera.

When the object is deformed by an external perturbation, the wavefront reflected from it is slightly changed, while the wavefront coming from the reference beam doesn't change. A new speckle pattern is recorded by the CCD camera and the subtraction of the speckle patterns registered for the deformed and non-deformed conditions provides the correlation fringes.

The correlation fringes (Fig. 10a) are numerically treated to remove the undesired noise and enhance the contrast allowing to obtain the phase contrast maps (Fig. 10b), from which it is possible to measure the displacement field with high accuracy [17].

The experimental data were used to setup a numerical model for the prediction of internal damage extension. A Finite element (FE) model in ABAQUS/EXPLICT environment has been used to numerically simulate the behavior of the composite plates.

In figures 11 the exploded FEM model is presented. Multipoint tie constraints have been placed between the impact area and the rest of the impacted panel to create different meshes (a finer mesh for the impact area and a coarser mesh for the rest of the model) and to optimize the computational cost without compromising the accuracy of the results.

As shown in figure 11 Cohesive elements have been adopted to model the inter-laminar damage formation and evolution in the analyzed composite plate. 
The cohesive behavior is represented by a bilinear traction-separation law characterized by an initial damage phase and a damage evolution phase. The failure criterion used to identify the damage initiation (first phase of the traction-separation law) for the cohesive elements is the quadratic nominal stress criterion while the complete failure in cohesive elements is found when the linear criterion involving energy release rates is satisfied:

$$
\left(\mathrm{G}_{\mathrm{I}} / \mathrm{G}_{\mathrm{Ic}}\right)+\left(\mathrm{G}_{\mathrm{II}} / \mathrm{G}_{\mathrm{IIc}}\right)+\left(\mathrm{G}_{\mathrm{III}} / \mathrm{G}_{\text {IIIc }}\right)=1
$$

where the parameter $G_{j}$ (with $\left.j=I, I I, I I I\right)$ is the Energy Release Rate associated to the fracture mode $j$ and $\mathrm{G}_{\mathrm{jc}}$ is the critical Energy Release Rate associated to the fracture mode $\mathrm{j}$.

In figure 12 an Example of the performed numerical analyses is given pointing out the capability of the numerical model to simulate the concurring delamination onset at several ply interfaces.

Some of the non destructively investigated specimens were cut by a diamond saw along to perpendicular directions passing through the centre of the impact point and then visually inspected by an optical microscope. The latter, having a $25 \mathrm{x}$ of magnificence, allowed to measure the extension of the delamination in both the perpendicular directions. The results were compared with what obtained by the non destructive and numerical evaluation.

At the end, in addition, glass layers of dry fibre under fabric form were overlapped following the stacking sequence $[(0,90)]_{\mathrm{n}}, \mathrm{n}=6,10,14$ and 16 , and impregnated by epoxy resin, SX10, to obtain four laminates resulting in nominal thicknesses in the range 1.8, 2.3, 4 and $4.6 \mathrm{~mm}$ and destined to low temperature impacts. The fibre volume fraction was $\mathrm{V}_{\mathrm{f}}=48 \%$.

The experimental low velocity impact tests have been performed following the same campaign as explained above and the updating of the falling weight machine by a thermal chamber allowed the tests at the low temperatures of $-25^{\circ} \mathrm{C}$ and $-50^{\circ} \mathrm{C}$. Unfortunately, the lower thickness didn't give good results so it was not considered in the present paper. 


\section{Load curve}

The complete load displacement curve recorded during each experimental low velocity impact test up to penetration, was revealed a map of the behavior of the materials under dynamic loading conditions [18]. The study of the load curve is thus very important in the understanding of the phenomenon. It revealed, in fact, a number of very useful information about the phenomenon and the response of the laminates [18]. In Fig. 13a), load curves recorded during the indentation tests at increasing impact energy were overlapped, whereas in Fig. 13b) the same curves were overlapped to the complete penetration one. A perfect overlapping of the first part of the curve was noted, revealing the perfect repeatability of the experimental tests. At the increasing of the impact energy, an increasing of the absorbed energy, the area between the load and unload part of the curve, was noted.

When the contact force is sufficiently low, the material response is approximately linear. This behaviour is preserved up to the first load drops (arrows in Fig. 13), where the damage under delamination form starts, resulting in a loss in local rigidity. After that, the load steadily increases again, until significant force oscillations, indicating other damage like fibre failure that propagates inside the laminate along the thickness up to all the layers are progressively broken and the perforation process is completed. In correspondence of the load drops, the energy values for the indentation tests were measured.

The load curves recorded in all the different test conditions were used to evaluate the main impact parameters involved in the phenomenon like penetration energies and maximum forces, and the correspondent displacements. Penetration and maximum force have been measured on the load curves.

\section{Results and discussion}

\section{Indentation and Penetration}


In [18], the results of low velocity impact tests on CFRP laminates, different in thickness, lay-up, and material system, were used to assess a power law equation (Eq. 2), valid for a quite large class of laminates, for the prediction of the impact energy, $\mathrm{U}$, from an indentation measurement, $\mathrm{I}$ :

$$
I=I_{o} \cdot\left(\frac{U}{U_{p}}\right)^{\beta}
$$

In Eq. $2, \mathrm{I}_{\mathrm{o}}$ and $\beta$ are two constants calculated by the best-fit method, $\mathrm{I}_{\mathrm{o}}=6.77 \mathrm{~mm}$ and $\beta=$ 2.535 and $U_{p}$ represents the penetration energy, the energy necessary to completely penetrate the laminate.

In [19], the previously found power law was revealed not able to follow the experimental trend at higher impact energy values whereas an exponential indentation law was found to fit well the experimental points for higher non dimensional impact energy values:

$$
I=k \cdot\left(10^{\gamma \cdot \frac{U}{U_{p}}}-1\right)
$$

In Eq. (3), $U$ is the impact energy, $U_{p}$ the perforation energy, $k$ and $\gamma$ constants to be experimentally determined. For the determination of the constants, the following relationship is easily obtained from Eq. (3):

$$
\log \left(\frac{I}{k}+1\right)=\gamma \cdot \frac{U}{U_{p}}
$$

Plotting the term on the left against the ratio between impact and penetration energy, would result in a straight line passing through the origin, provided the correct value is adopted for $\mathrm{k}$. The constant $\gamma$ could be evaluated from the slope of the straight line. 
In Fig. 14, it was done for the data generated inside the present research. Using $\mathrm{k}=0.288$, value valid for carbon laminates [19], a linear trend through the origin was revealed good to approximate the data with a very good regression coefficient $\left(R^{2}=0.99\right)$. From the slope, $\gamma=0.649$ was measured.

It is possible to assert that the indentation law seems to confirm the quite general applicability, being scarcely affected by the fibre type and orientations and by the matrix type. This results represents also an affordability index of the new fabrication technology here adopted.

However, in the above presented studies, two constants appear and the tup diameter was not explicitly taken into account. In [20], the effectiveness of a new empirical model was verified on glass fibre laminates and it was validated in [21] on basalt fibre laminates:

$$
I=\alpha \cdot D_{t} \cdot \frac{U / U_{p}}{1-U / U_{p}}
$$

with $\alpha$ being a material-dependent parameter. $\mathrm{D}_{\mathrm{t}}$ is the tup diameter.

The model showed the advantage to explicitly account for the tup diameter and a single material constant is necessary to be experimentally determined to predict the indentation as a function of the non dimensional impact energy. In $[20,21]$ it was noted that this constant could be assumed as an index for the indentation sensitivity, on the basis of which different materials can be ranked.

In the present research, the model was applied on carbon laminates made by pulsed infusion technology. In Fig. 15, the indentation measurements carried out here were compared to the results obtained on isotropic and orthotropic glass fibre in phenolic matrix laminates from [20] used to validate the model:

To evaluate the constant $\alpha, \mathrm{I} / \mathrm{D}_{\mathrm{t}}$ was plotted against the quantity $\mathrm{K}=\left(\mathrm{U} / \mathrm{U}_{\mathrm{p}}\right) /\left(1-\mathrm{U} / \mathrm{U}_{\mathrm{p}}\right)$ on the right of Eq. 5. This results in a straight line passing through the origin, having slope $\alpha$.

From the figure, the value 0,0249 was found, different from what found in [20,21] for glass and basalt laminates, 0,08 and 0, 019 respectively. Moreover, the here found value is very different also 
from the value 0,069 found in [20] about CFRP laminates obtained overlapping dry fabric carbon fibre layers. Since the materials studied in the present research were obtained from unidirectional carbon fibre, the different $\alpha$ value denotes a sensible dependence also on the stratification.

Since the sensible differences noted between the different material systems studied up to now, it is possible to confirm the conclusion that $\alpha$ is a material-dependent parameter. As done in [20, 21], it is possible to conclude that what found about a simple model including only the diameter of the impactor and the ratio between the impact energy and the perforation one, to identify a material independent parameter characterising the indentation depth, is valid. Of course, more data will be used to confirm the statement.

However, to be able to predict the impact energy from a simple indentation measurement, that represents the main meaning of the indentation law (Eq. (3) and (5)), also the power law previously found [22] and reported in equations (6), for the prediction of the penetration energy, $U_{p}$, has to be validated.

$$
U_{p}=K \cdot\left(t \cdot V_{f} \cdot D_{t}\right)^{\alpha}
$$

$\mathrm{K}$ and $\alpha$ are two material parameters to be experimentally determined.

The law evidenced the very important role played by the fibre content and it is able to collect data obtained on different laminates and in different test conditions. Since the single thickness investigated in the present research, only one experimental point useful to assess the prediction law was here obtained. It was add in Fig. 16 to the data from literature $[19,22]$ about carbon laminates different in thickness and impacted with different tup diameters, $\mathrm{D}_{\mathrm{p}}$ : the perfect location along the single master curve collecting all the data, confirm the validity of the model and once again, it represents also an affordability index of the new fabrication technology here adopted.

\section{Delamination}


In Fig. 17, the results from the three non destructive investigations carried out in this research and evaluated on the same specimen, were compared. It was demonstrated [23] that in the $2 \mathrm{~mm}$ thick and thinner specimens, the bending effect is higher than the local one due to the contact between impactor and the surface of the material, and the delaminations are larger on the opposite side respect to the impacted one (cone shape). For this reason, in some cases, the delaminations are not visible on the impacted surface and the ND measurements were, in general, carried out on the backside.

From the first quick visual comparison, it is possible to note the ability of the three different techniques in investigating the delamination. Moreover, it is very important to underline the very clear lobe shape, typical of the delamination between layers differently oriented, evidenced by the thermal analysis and by the holographic technique and confirmed by the more largely used and reliable US C-scan. The fact that the optical technique clearly evidenced the lobe of the delamination represents a very interesting result since the latter method can usually investigate the modifications that happen on the surface or in the subsurface area, whereas the delamination is an internal damage. The explanation could be found in the fact that the delaminated internal layers cause, through layer by layer, a change out of the plane of the entire laminate that the sensibility of the ESPI, related to the laser wavelength, is able to capture.

In Fig. 18, the average values of the measurements of the delamination, in terms of maximum lenghts (a) and maximum widths (b), measured on all the impacted specimens at different impact energies and by all the NDE used in this work, are reported: very satisfactory agreements were found.

The general small lower values obtained by the optical techniques could be due to the fact that the larger extension of the delamination happens in the middle of the thickness or between layers far from the contact point and they were evidenced like darker areas around the lighter ones of the surface local damage. In this way, since the edges are not well defined, it is possible that a little portion of the damage was not considered in the measurement and analysis. 
However, considering that the delamination happens inside the material, what obtained by this analysis could be considered completely satisfactory.

As a confirmation of what above mentioned about the cone shape, in Fig. 19, thermographic images of the specimens impacted at the three different energies chosen on the load curve, are shown. It is possible to note that no damage was observed on the front side (Fig. 19a). On the contrary, the delamination extension is clearly visible on the back side at a surface level (Fig. 19b). By probing in deep using a lower lock-in frequency (Fig. 19c), the impact damage appears further more highlighted in the phase image (Fig. 19c).

In Fig. 20, thermographic images of a second series of specimens impacted at the three different energies are shown. It is possible to note that, in this case, the damage produced at the higher energies was observed also on the front side, and it became very clear by probing at a low lock-in frequency $(0.075 \mathrm{~Hz})$, which means a more deep penetration within the material (with respect the surface level) (Fig. 20a)). It is due to the local contact effect between the impactor and the surface of the material. On the back side (Fig. 14b)), the delamination extension is very clear at a surface level (18b) and it is more evident by probing with a lower lock-in frequency 20c).

In Fig. 21, the results in terms of damage extension obtained once again on the backside, by thermography and holography, on specimens impacted at $\mathrm{U}=10 \mathrm{~J}$, were compared with the results from numerical simulations. Very good agreement was reached. More details about the numerical study, out of the aim of the present paper, can be found in [24].

In table 1, the front side measurements carried out on specimens of the second series of tests, were added to the results reported in Fig. 18 a). A very good agreement was found also in this case between thermography and ESPI techniques and the numerical analysis.

To compare the data with direct visual measurements, some impacted specimens, one for each impact energy, were at the end cut along both longitudinal and transversal perpendicular directions passing though the central impacted point and the sections were observed by an optical microscope 
(Olympus SZ60) 25x of magnification. The length of the impacted area was identified also after highlighting it with aim of a special paint (red die penetrant) and then photographed and measured thanks to a graduated scale available on the equipment. In this way it was possible an evaluation of the delaminated extensions and a measurement of their dimensions. More interesting, in this way it was possible to observe the location of the principal delamination along the thickness.

In Fig. 22, an example of the image of the section of the specimen impacted at $13 \mathrm{~J}$ was reported. It was obtained by combining, through the program Adobe Photoshop CC 2014, the two sectioned parts. In the figure, the very clear delamination is located on the opposite side respect to the impacted one.

In Table 2, the results from the destructive tests were reported together with the data showed above and obtained by the NDE. It is possible to see the general agreement except for the lower impact energy, where it was impossible to measure any delamination about the length and an underestimation was found along the width direction. It denotes the importance of the cut by the diamond saw that eats at least $1 \mathrm{~mm}$ of material, loosing information. This is an important aspect to consider in order to plan the right distance from the central line and the right location of the cut.

The maximum extensions of the delamination, lenght $d$, measured by all the ND and destructive techniques on the specimens analysed in the present research, were plotted in Fig. 23 against the impact energy. An exponential law having equation:

$$
\mathrm{d}=5,85 \mathrm{e}^{\wedge(0,156 \mathrm{U})}
$$

was revealed able to well approximate the results.

The measured delaminated areas, A, obtained by the different technologies here investigated, are compared in Fig. 24 against the impact energy, U. An agreement was noted in some situations even if the agreement between the different techniques adopted is a function of the impact energy. For example, the agreement between thermography, numerical and ESPI is very good when the damage was produced by $10 \mathrm{~J}$ of energy whereas at $6 \mathrm{~J}$ of impact energy, thermographic and numerical 
models underestimate the damage found by US in agreement with ESPI. In general, US C-scan always observed the larger extension. However, it is reasonable to assert that although the differences noted, the general trend of the delaminated area as a function of impact energy, was respected. It is in addition useful to note the difference between the results obtained by ESPI on the two different sides: front and back. As expected since the above mentioned bending effect, the back side delamination was found larger than the front side. The latter results confirm the sensitivity of the technique in inspecting the impact damage on composite laminates.

However, in literature [25] there is a debate about the relative merits of using force or energy as a scale parameter for the impact damage and thus, about which is the right parameter for the study and the prediction of the delaminated area. Some researchers [25] believe that the maximum force, $\mathrm{F}_{\max }$, instead the impact energy, $\mathrm{U}$, was revealed as the right parameter. The approach based on impact force works well in many applications, especially when the onset of damage has to be determined for different plates or impactor geometries [26, 27]. In Fig. 25, the data obtained in the present work from ESPI technique were added to data from literature [25] and plotted against the maximum force, $\mathrm{F}_{\max }$.

As it is possible to see, all the experimental data well fit the power law having equation:

$$
A=\eta \cdot F_{\max }^{\beta}
$$

where $\mathrm{A}$ is the delaminated area and by the minimum square method, the values of the two constants $\eta=4,06 \mathrm{~mm}^{2} / \mathrm{N}^{\beta}$ and $\beta=3,1$, have been obtained. The impact force could be, thus, used as a parameter to compare and to predict impact damage in structures from coupon tests [25].

The importance of the force was highlighted also by Zhang [28] that tested three different thicknesses QI laminates plates and plotted the damage area versus the impact load, showing the existence of a threshold for the onset of damage. She observed that as the contact load exceed the threshold value, the damage size increases very rapidly. Davies et al. [29] proposed a simple 
fracture mechanics model based solely on Mode II shear fracture to determine the onset of delamination in a simply supported axisymmetric plate. This model was used by Davies and Zhang [30] and Zhang [28] to calculate the critical impact load or threshold value $\mathrm{P}_{\text {cr }}$ given by:

$$
P_{c r}{ }^{2}=\frac{8 \pi^{2} E t^{3} \xi_{I I C}}{9\left(1-v^{2}\right)}
$$

where $\mathrm{t}$ is the laminate thickness, E the flexural modulus, $v$ is the Poisson's ratio, and $\xi$ is the critical value of the energy release rate for mode II fracture. Eq. (9) predicts that the critical load for the beginning of the delamination propagation, is proportional to $t^{3 / 2}$. Results also found by the authors in [18].

\section{Low temperature impact tests}

The impact tests at the two different low temperatures of $-25^{\circ} \mathrm{C}$ and $-50^{\circ} \mathrm{C}$, had the scope to investigate the dynamic behavior of composites of Naval Interest. Hereafter the results obtained after the analysis carried out as done at room temperature on glass fibre laminates.

\section{Load-displacement curve and energy}

Since the importance of the load curve as explained above, the force-displacement curves were recorded in the different temperature conditions and compared to the room condition to highlight the differences (Fig. 26).

The effect of the decreasing temperature on the load curve is similar to the effect of the increasing thickness: higher maximum force, higher initial rigidity and higher energy values were noted. In Fig. 26, the complete load-displacement curves obtained from tests up to penetration, were reported for example for the higher thickness investigated (16 layers). The same behaviour was noted for the 10 and 14 layers specimens.

\section{Penetration energy}


The penetration energy, $\mathrm{U}_{\mathrm{p}}$, was measured for of all the temperatures and it was noted that higher energies were necessary to penetrate the same laminates at the decreasing of the temperature (Fig. 27). The results were related to the more brittle behaviour of the laminates under dynamic loading at low temperatures [31]. It results, in fact, in the additional brittle damage of a bigger number of matrix cracks whereas at room temperature an higher part of energy is spent in the elastic deflection of the panel.

Interestingly, the penetration energy power law showed in Eq. 6, obtained from Fig. 28 was confirmed with a very good agreement of the exponent $\alpha=1.4\left(\mathrm{k}=0,82 \mathrm{~J} / \mathrm{mm}^{\beta}\right)$.

\section{Indentation depth and delaminated area}

The behaviour was confirmed to be more brittle at low temperatures by the results about the indentation depth: the plastic deformation on the surface of the laminates due to the indentermaterial contact effect, increases at the increasing of temperature and the increasing is more sensible as the impact energy and the thickness increase (Fig. 29).

Plotting in Fig. 30, the same values of indentation against the impact energy, a linear increase for the thicker laminates was noted (Fig. 30b) whereas a general logarithmic trend with a horizontal asymptote was evidenced for the thinnest laminates at low temperatures (Fig. 30a). It means that for the lower thicknesses the indentation increases up to a certain value of the impact energy after that it becomes constant. In the range of the investigated impact energies, the thickest laminates showed a higher volume for a big number of brittle damages.

In the following picture, the delaminated area, A, measured by US, was plotted against the impact energy, U, for the 16 layer. In general, at the decreasing of the temperature, an increasing of the damage extension was observed and the increasing is more evident at the increasing of the impact energy. However, while the 10 and 16 layers laminates exhibited very similar delaminations, for all the temperature conditions tested in this work, when impacted at $5 \mathrm{~J}$, different values and a smaller delamination at $\mathrm{T}=-50^{\circ} \mathrm{C}$ were measured on 14 layers impacted at the same energy. 
The extension of the delamination was found to be larger, at the increasing of the thickness, also at lower temperatures confirming the relative importance of the bending effect predominant for the thinner laminates and the shear one, more important in thick laminates.

Since the open debate [25] above mentioned, about the relative importance of the impact energy or the maximum force in governing the delamination extension, the delaminated area was plotted against the maximum load. In Fig. 32 the trend obtained for the laminates made by 16 layers was shown for example. Very interestingly, all the experimental data recorded for all the different thicknesses, followed a single linear trend, irrespective of the temperature.

Once again the maximum load is revealed an important key parameter to understand the damage evolution in impacted laminates.

\section{Conclusions}

Impact tests at low velocity have been carried out on composite laminates made by an innovative fabrication technology called Pulsed Infusion. The results obtained from the information given by the load-displacement curve in terms of forces and energies, were used to validate semiempirical and numerical models already existing in literature. After loading, the specimens were destructively and non destructively observed at the aim to investigate the impact damage. The indentation depth, measured by a confocal microscope, validated two semiempirical models for the prediction of the impact energy and the determination of an index for the indentation sensitivity dependent on the material. Different NDT were adopted and the results compared in terms of delamination length and extension and then compared to the results from the simulations. Very interestingly, the maximum load was revealed as the right parameter to compare and predict impact damage in structures from coupon tests.

In general, good agreement were found from the models validations and from the comparisons of the measurements. In particular, the research highlighted the efficiency of ESPI: it was revealed, in fact, a valid tool to investigate the internal and external impact damage on composite laminates 
being able to supply precise information in a very fast way and in full-filed modality. Also the impact tests carried out at low temperatures on glass fibre laminates have given interesting results about the more brittle behaviour of the materials respect to the room conditions and the importance of the maximum force in investigating the delamination.

In particular: higher energies were necessary to penetrate the same laminates at the decreasing of the temperature and the brittle behaviour at low temperature was confirmed by the lower indentation depths respect the room conditions since the indentation represents the plastic deformation left on the surface of the laminates by the indenter-material contact during the load.

\section{ACKNOWLEDGMENTS}

The authors gratefully acknowledge Dr Yapa D.S. Rajapakse from the Office of Naval Research, Program Manager of the ONR Solid Mechanics Program, Grant n. N00014-14-1-0380, for the financial support at the present research. A further acknowledgment to Dr Yapa D.S. Rajapakse for the very high scientific contribution and the financial (through ONR) support to the Draf2014 Conference.

\section{References}

[1] V. Lopresto, G. Caprino and C. Leone, "A New Damage Index For The Indentation Depth Evaluation Of Composites Under Low Velocity Impact Loads”, Polymer Composites, 34/12, pp. 2061-2066 (2013).

[2] F.K. Chang, H.Y. Choi, and H.S. Wang, "Damage of laminated composites due to low velocity impact", 31st AIAA/ASME/ASCE/AHS/ASC Structures, Struct. Dyn. and Mater. Conf., Long Beach, CA, April 2-4, 1990, pp. 930-940.

[3] M.G. Stout, D.A. Koss , C. Liu, J. Idasetima, "Damage development in carbon/epoxy laminates under quasi-static and dynamic loading", Compos. Sci. and Technol., Vol. 59, 1999, pp. 2339-2350

[4] Azouaoui K, Recha S, Azari Z, Benmedakhene S, Laksimi A, Pluvinage G., "Modelling of damage and failure of glass/epoxy composite plates subject to impact fatigue", Int J Fatigue (2001) 23: 877-85 
[5] V. Lopresto, G. Caprino, "Damage mechanisms and energy absorption in composite laminates under low velocity impact loads", Chapter on Book: Dynamic Failure of Composite and Sandwich Structures, Series: Solid Mechanics and Its Applications, Vol. 192, Abrate, Serge, Castanié, Bruno, Rajapakse, Yapa D. S. 2013, 2013, I, 675 p. 492 illus., 332 in color. ISBN 978-94-007-5328-0. Due: November 30, 2012. Springer Ed.

[6] X. Zhang, "Impact damage in composite aircraft structures-experimental testing and numerical simulation", Proceedings of the Institute of Mechanical Engineers, 1998, pp. 245-259.

[7] G.A.O. Davies, X. Zhang, G. Zhou, S. Watson, "Numerical modelling of impact damage", Composites, Vol. 25, No. 5, 1994, pp. 342-350.

[8] MR Ricciardi, V Antonucci, M Durante, M Giordano, L Nele, G Starace, A Langella, "A new cost-saving vacuum infusion process for fiber-reinforced composites: Pulsed infusion", Journal of Composite Materials, Vol. 48, 2014, pp. 1365-1373

[9] Busse G., "Optoacoustic phase angle measurement for probing a metal", Appl. Phys. Lett., 35, 759-760, 1979.

[10] C. Toscano, A. Riccio, F. Camerlingo and C. Meola, "On the use of Lockin Thermography to Monitor Delamination Growth in Composite Panels under Compression", Science and Engineering of Composite Materials, 2013. ISSN: 0792-1233. Doi: 10.1515/secm-2013-0156

[11] Dillenz A., Zweschper T., Riegert G., Busse G., "Progress in phase angle thermography", Rev. Sci. Instr., 74, 417-419, 2003.

[12] A. Riccio, A. Raimondo, S. Fragale, F. Camerlingo, B. Gambino, C. Toscano and D. Tescione, "Delaminations buckling and growth phenomena in stiffened composite panels under compression. Part I: an Experimental Study", Journal of Composite Materials, 2013. ISSN: 0021-9983, doi: $10.1177 / 0021998313502741$.

[13] A. Riccio, A. Raimondo, Di Caprio and F. Scaramuzzino, "Delaminations buckling and growth phenomena in stiffened composite panels under compression. Part II: a Numerical Study", Journal of Composite Materials, 2013. ISSN: 0021-9983. Doi: 10.1177/0021998313502742. 
[14] L. Farge, Z. Ayadi, J. Varna, "Optically measured full-field displacements on the edge of a cracked composite laminate", Composites: Part A 39 (2008) 1245-1252.

[15] P. Ferraro, A. Ferraiuolo, S. Insera Imaparato, C. Voto, and K. A. Stetson, "On the holographic detection of core-to-skin disbonds in composite sandwich structures", Materials Evaluation 52, 1376-1381 (1994).

[16] P. Ferraro "Evaluation by Holographic Interferometry of Impact Damage in Composite Aeronautical Structures", Laser interferometry IV: Computer-aided interferometry; Proceedings of the Meeting, San Diego, CA, July 22-24, 1991 (A93-44185 18-35), Proc.SPIE Vol.1553 ,p.349-357.

[17] V. Pagliarulo, R. Palummo, A. Rocco, P. Ferraro, M.R. Ricciardi, V. Antonucci. "Evaluation of delaminated area of polymer/Carbon Nanotubes fiber reinforced composites after flexural tests by ESPI”, IEEE MAS proceedings, 2014, 6865922, pp. 211-215.

[18] G. Caprino, V. Lopresto, C. Scarponi and G. Briotti, "Influence of material thickness on the response of graphite fabric/epoxy panels to low velocity impact", Compos. Sci. and Technol. 59/15, 2279-2286 (1999).

[19] G. Caprino, A. Langella, V. Lopresto, "Indentation and penetration of carbon fibre reinforced plastic laminates", Composites Part. B, Vol. 34, 2003, pp. 319-25.

[20] V. Lopresto, G. Caprino, C. Leone, "A New Damage Index For The Indentation Depth Evaluation Of Composites Under Low Velocity Impact Loads", Polymer Composites, V 34/12 (2013), pp. 2061-2066, doi 10.1002/pc.22614, ISSN: 1548-0569.

[21] V. Lopresto, G. Caprino, C. Leone, A. Langella, "A Damage Index Of Indentation Sensitivity In Low Velocity Impact Conditions", in press on Polymer Composites.

[22] G. Caprino and V. Lopresto, "On the penetration energy of fibre reinforced plastics under low-velocity impact conditions”, Compos. Sci. Technol. 61/1: 65-73 (2001).

[23] G. Caprino e V. Lopresto "Macroscopic behaviour and fracture modes of CFRP panels transversely loaded at the centre", Proc. of ECCM11, 31 May- 3 June 2004, Rodi, Greece.

[24] Riccio, G. Di Felice, G. LaManna, E. Antonucci, F. Caputo, V. Lopresto, M. Zarrelli, "A Global-Local Numerical Model for the Prediction of Impact Induced Damage in Composite Laminates", Appl Composite Materials, 2013, Springer. 
[25] Jackson W.C. and Poe C.C. Jr, "The use of impact force as a scale parameter for the impact response of composite laminates", J. of Composites Technology and Research, Vol. 15, No. 4, 1993, pp. 282-289.

[26] Lagace P.A., Williamson J.E., Tsang P.H.W., Wolf E., Thomas S.A., “A preliminary proposition for a test method to measure (impact) damage resistance", J. of Reinforced Plastics and Composites, Vol. 12, No. 5, 1993, pp. 584-601.

[27] Poe C.C. Jr, "Relevance of impactor shape to non visible damage and residual tensile strength of a thick graphite/epoxy laminate", In Composite Materials: Fatigue and Fracture, Vol. 3, ASTM STP 1110, ed. T.K. O’Brien. American Society for Testing and Materials, Philadelphia, PA, 1991, pp. 501-527.

[28] Zhang X., "Impact damage in composite aircraft structures-experimental testing and numerical simulation”, Proceedings of the Institute of Mechanical Engineers, 1998, pp. 245-259.

[29] Davies G.A.O., Zhang X., Zhou G., Watson S., "Numerical modeling of impact damage", Composites, Vol. 25, No. 5, 1994, pp. 342-350.

[30] Davies G.A.O., Zhang X., "Impact damage prediction in carbon composite structures”, Int. J. of Impact Engineering, Vol. 16, No. 1, 1995, pp. 149-170.

[31] S. Putić, M. Stamenović, B. Bajčeta, P. Stajčić, S. Bošnjak, "The influence of high and low temperatures on the impact properties of glass-epoxy composites", J. Serb. Chem. Soc. 72 (7) (2007), pp. $713-722$. 


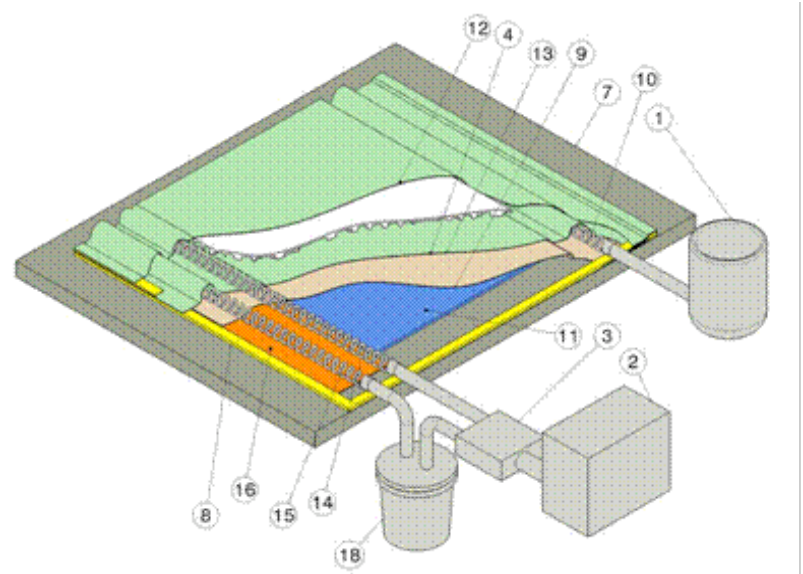

1. Resin Tank

2. Vacuum Pump

3. Pressure Control System

4. Pressure Distributor

5. Lower Chamber

6. Upper Chamber

10. Resin Inlet System

11. Reinforcement

13. Bag

14. Intake System

Figure 1: Pulsed Infusion apparatus

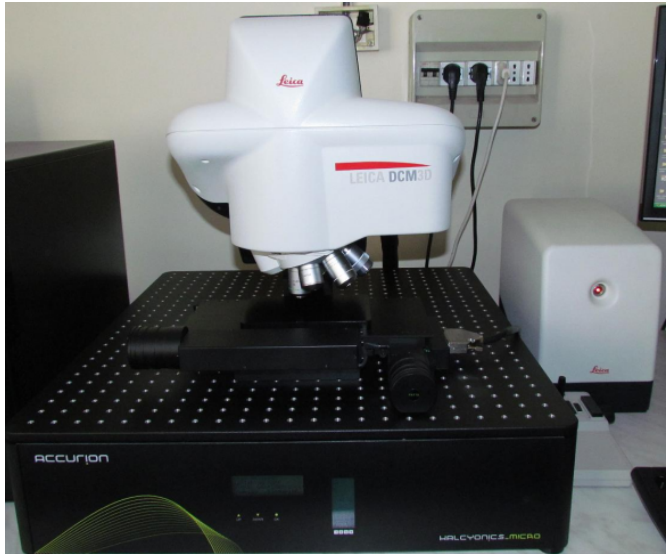

Figure 2: Confocal Microscope LEICA DCM3D 


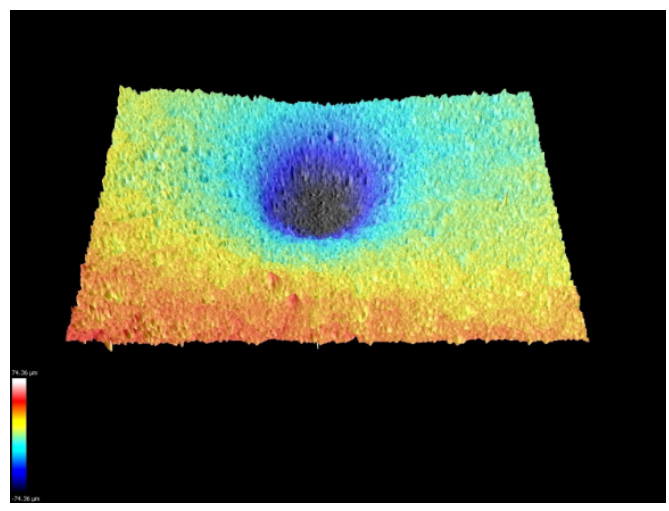

Figure 3: Surface image recorded by the confocal microscope after the impact test.

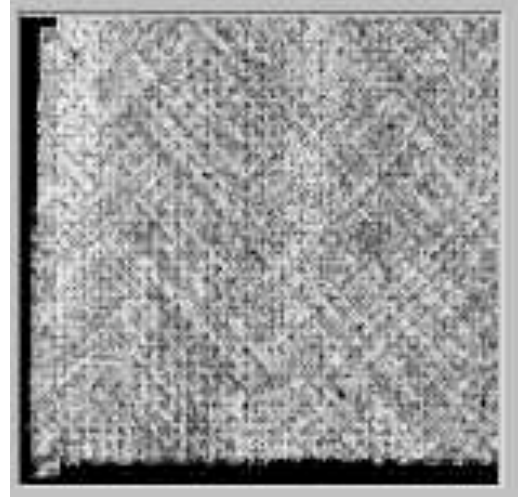

a)

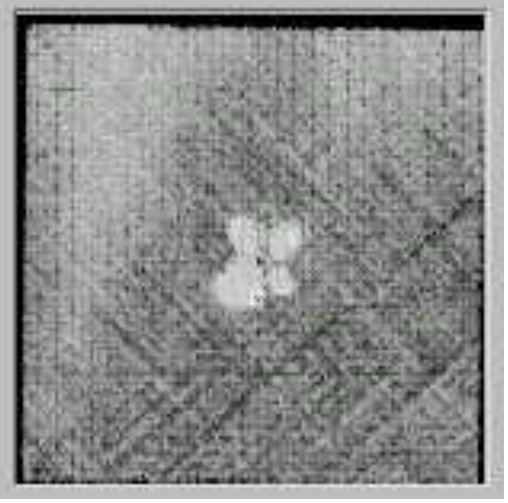

b)

Figure 4: C-scan inspection of virgin (a) and impacted (b) specimen.

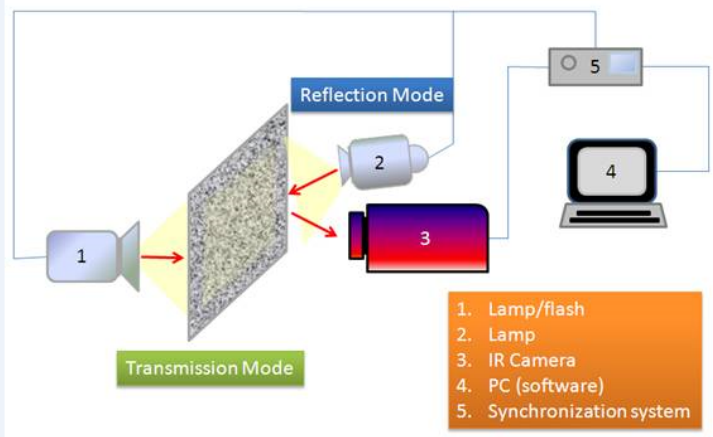

Figure 5: Lock-In Thermography set up. 


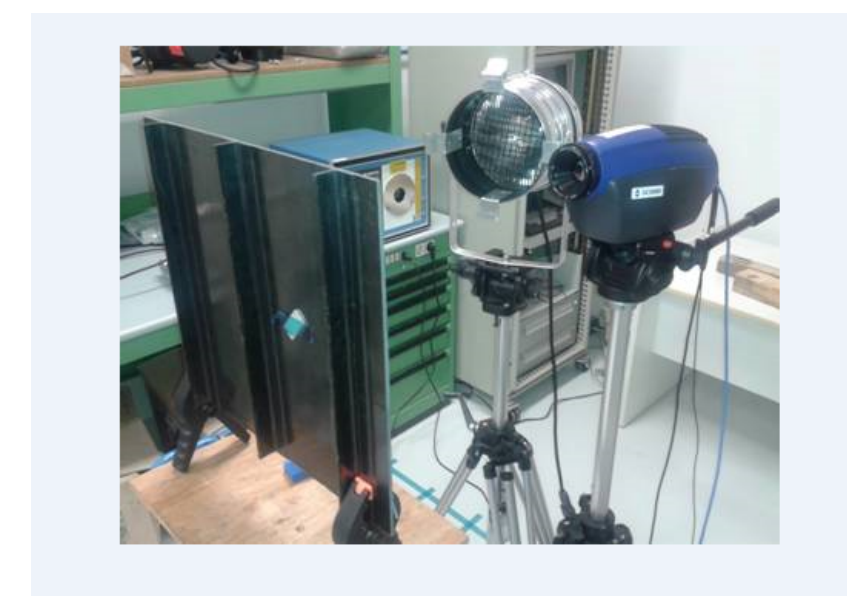

Figure 6: Lighting system and thermal camera.

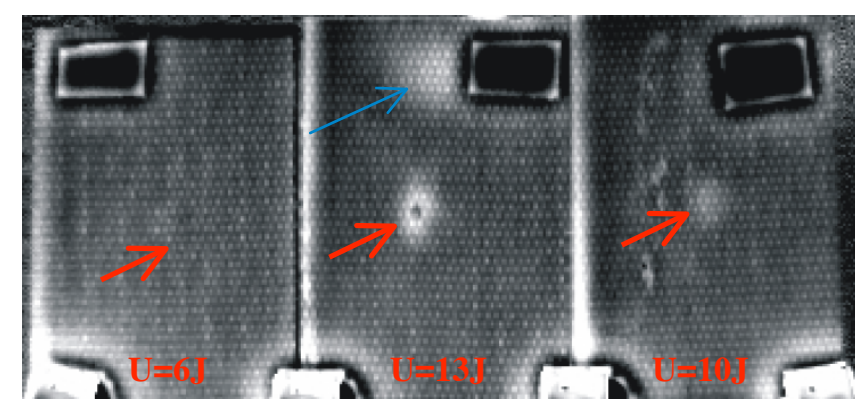

Figure 7: Phase maps of the coupons impacted with energies of 6, 13, and $10 \mathrm{~J}$ (front side).

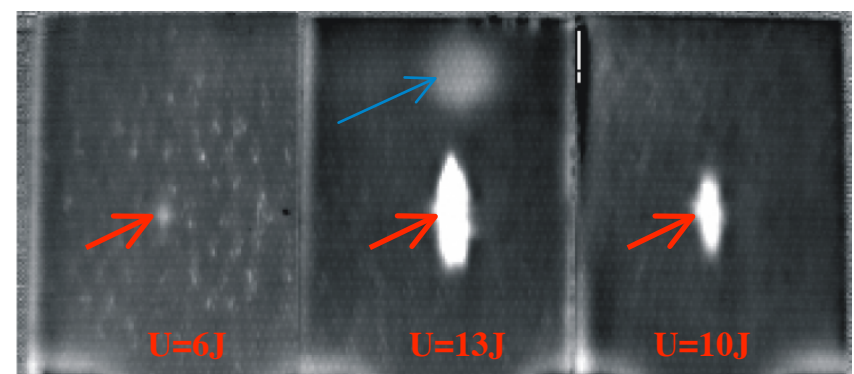

Figure 8: Phase maps of the coupons impacted with energies of 6,13, and $10 \mathrm{~J}$ (rear side inspection). 


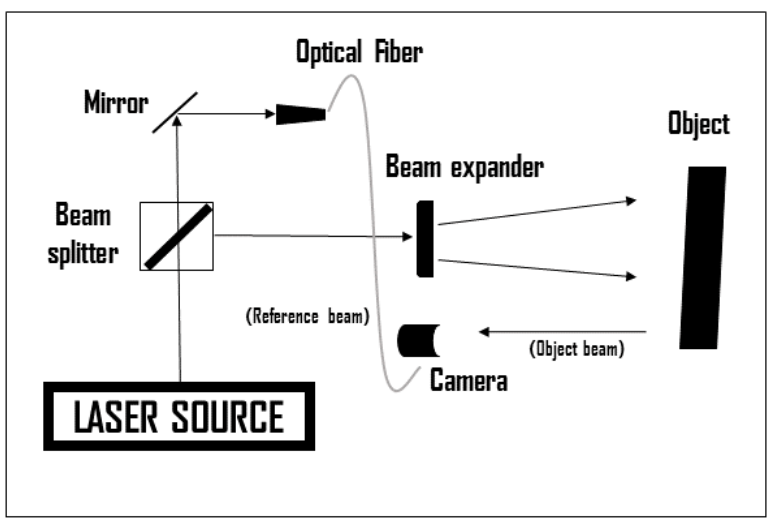

Figure 9: Components layout for the ESPI system.

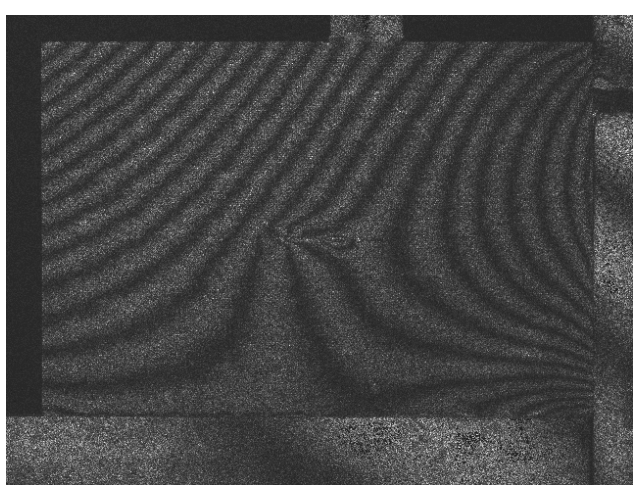

a)

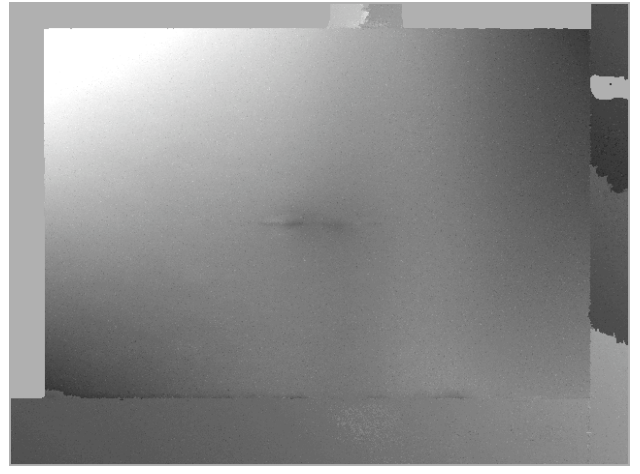

b)

Figure 10: a) correlation fringes, b) the unwrapped phase contrast map

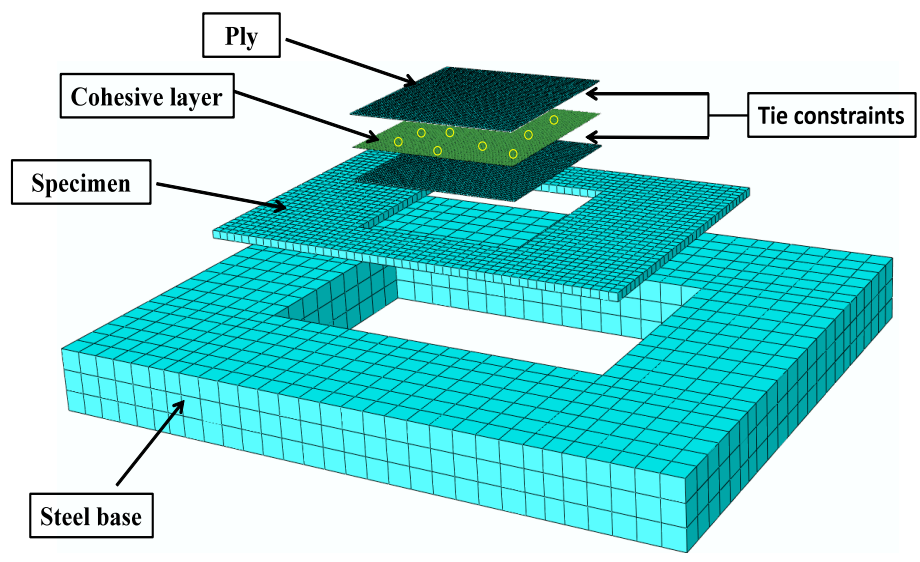

Figure 11: exploded FEM model 


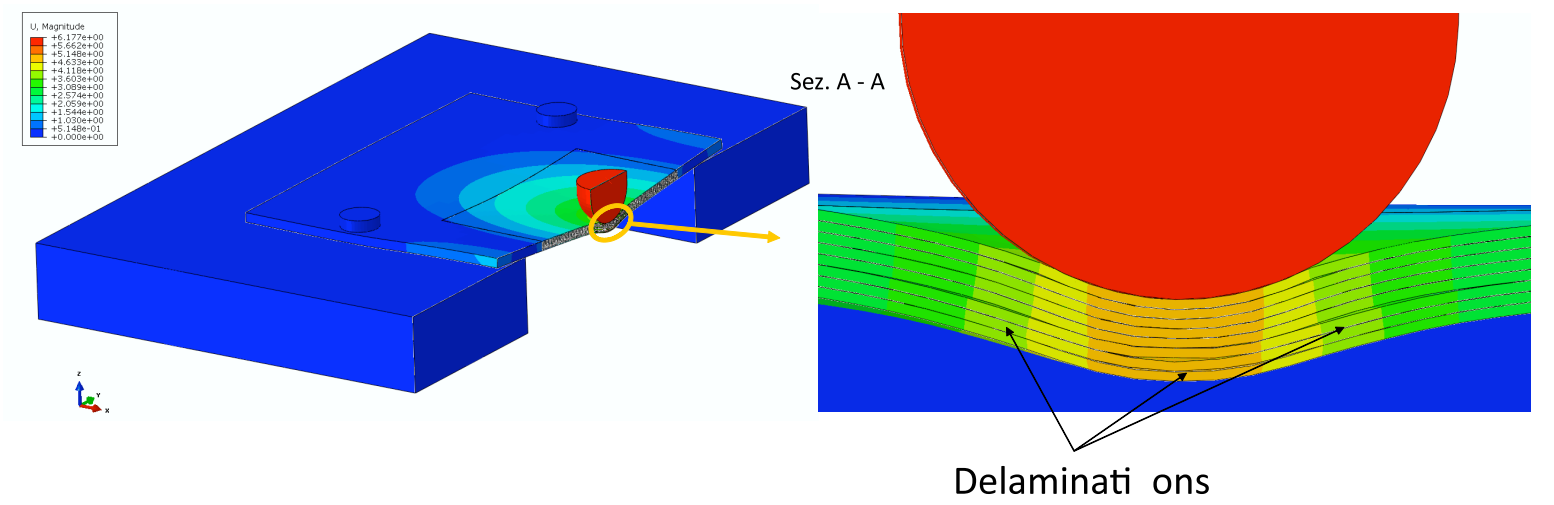

Figure 12: Example of the simulation of the impact behaviour with delaminations formation

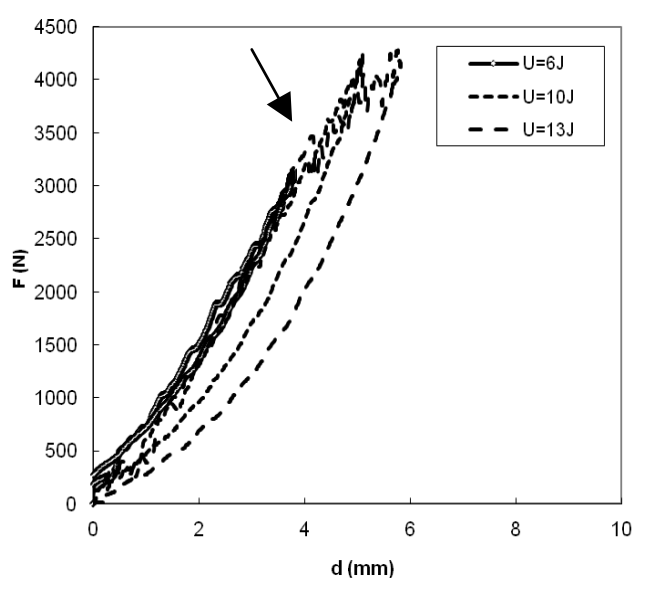

a)

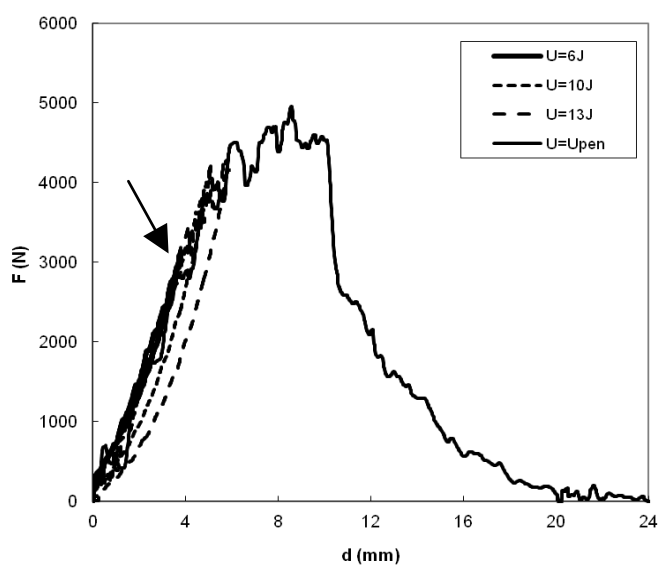

b)

Figure 13. Load-displacement curves. a) indentation tests: $\mathrm{U}=6 \mathrm{~J} ; 10 \mathrm{~J} ; 13 \mathrm{~J}$. b) overlapping with complete penetration curve. 


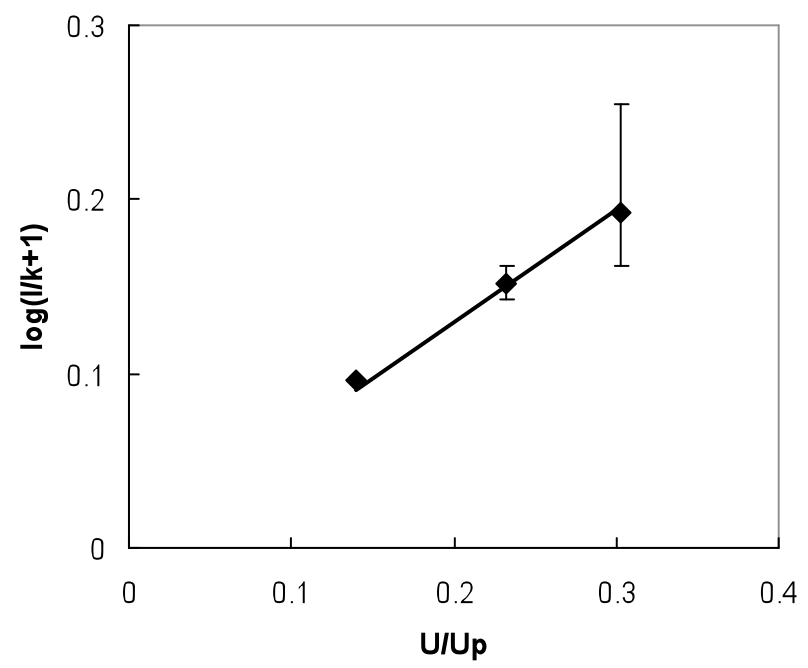

Figure 14: Indentation law for the research of the constants $\mathrm{k}$ and $\gamma$.

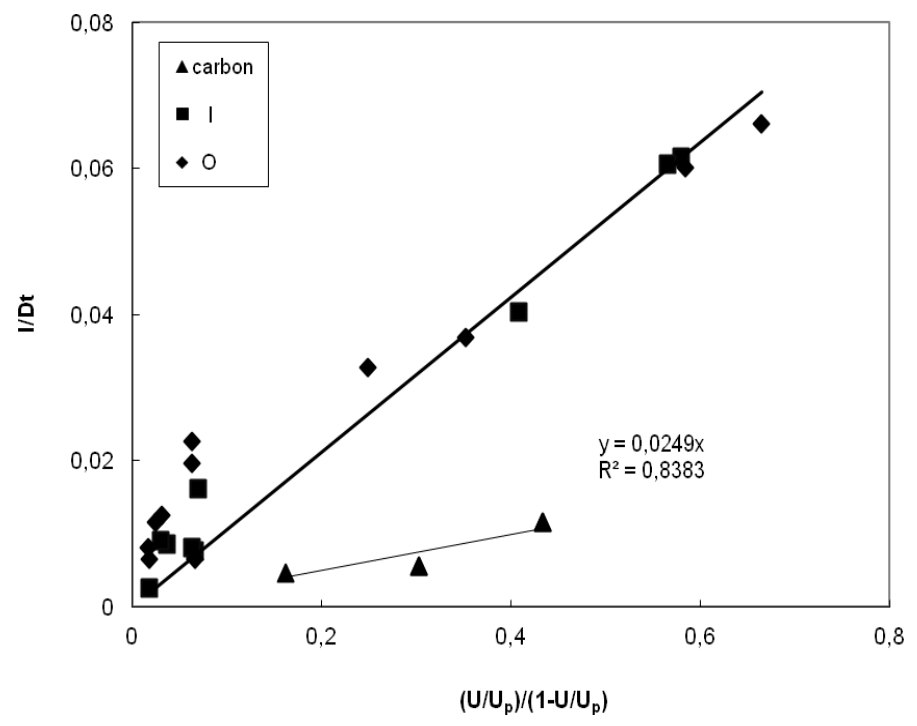

Figure 15: Non-dimensional indentation, $\mathrm{I} / \mathrm{D}_{\mathrm{t}}$, for $\alpha$ calculation. Material: GFRP, I and $\mathrm{O}$, and CFRP. 


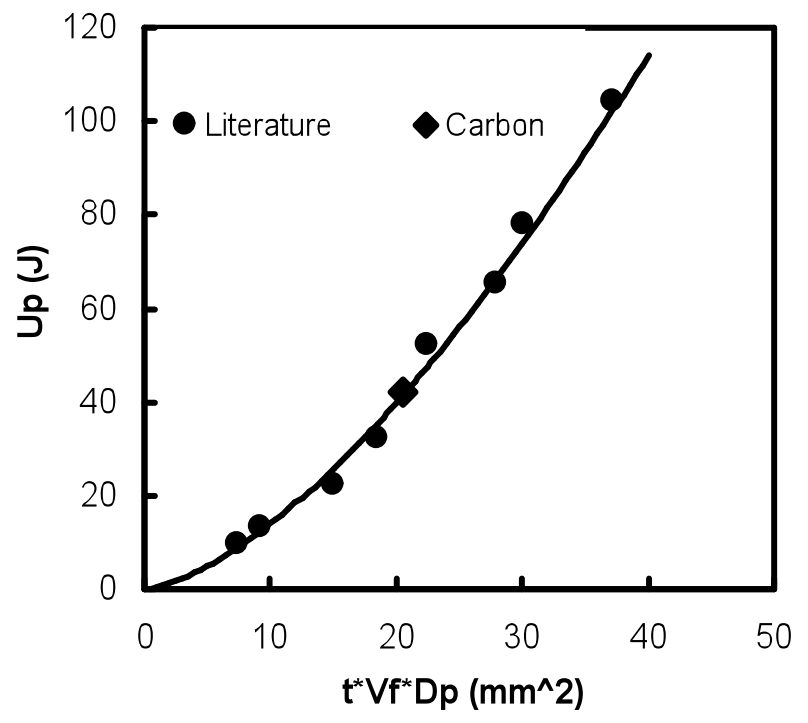

Figure 16: Model validation for the prediction of the penetration energy, $U_{p}$.

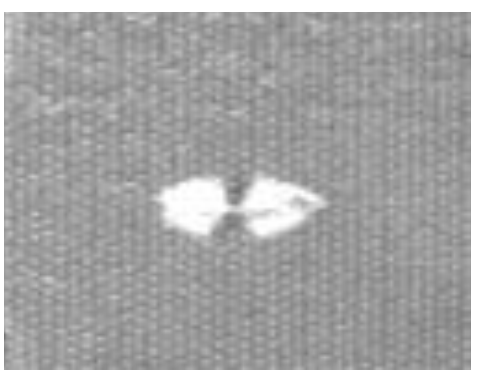

(a)

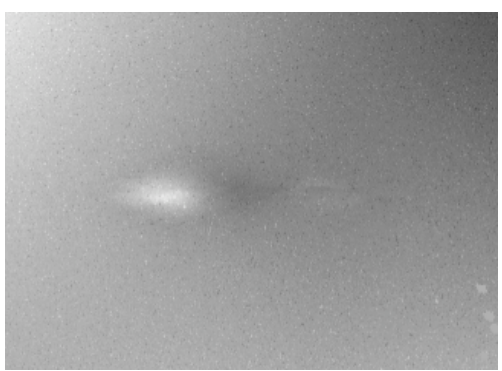

(b)

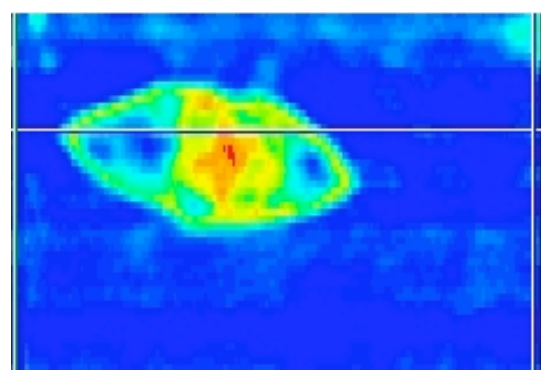

(c)

Termography Holography

Figure 17: NDE: a) Thermografy; b) Holography; c) US. U=13J. Backside. 


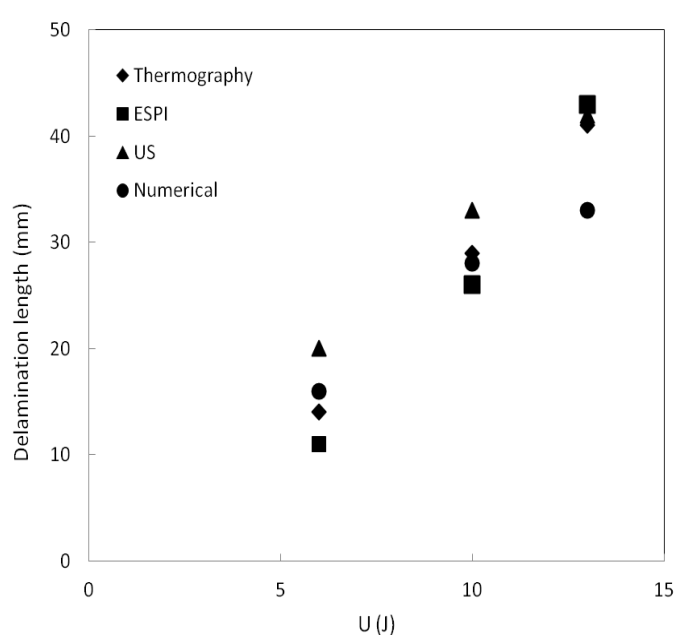

a)

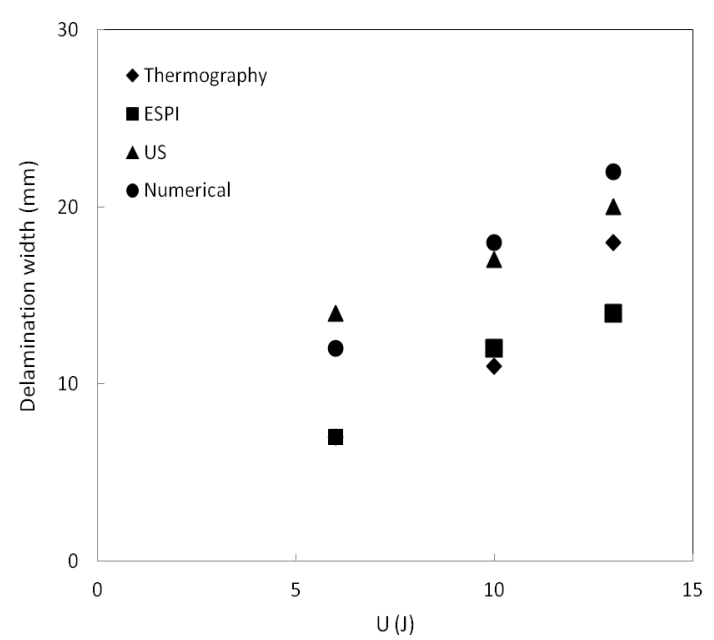

b)

Figure 18. Comparison between the results of the different NDE used in the work.

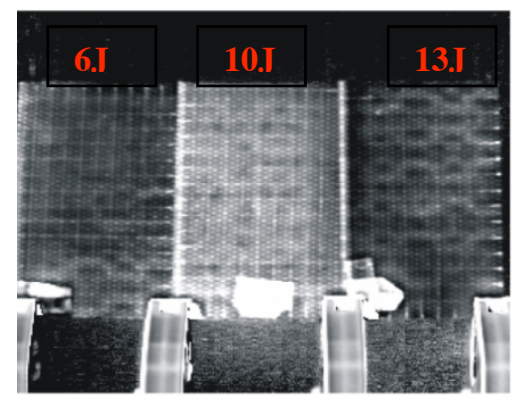

a)

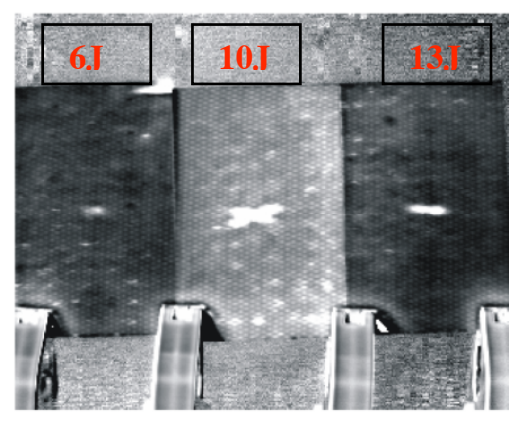

c)

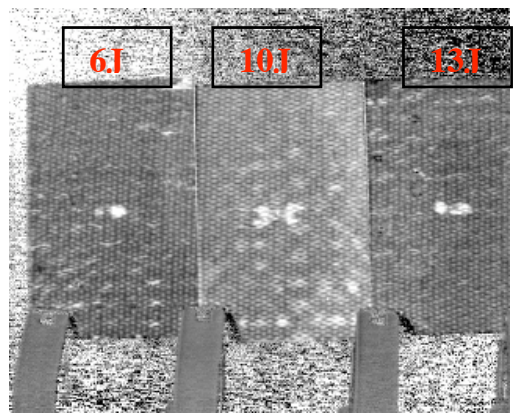

b)

Figure 19: a) phase image @ $0.075 \mathrm{~Hz}$ of the front side; b) phase image @ $1 \mathrm{~Hz}$ of the rear side; c) phase image of the rear side @0.05Hz. 


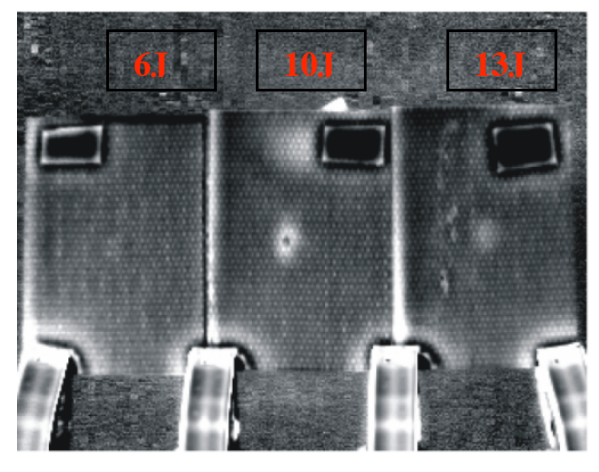

a)

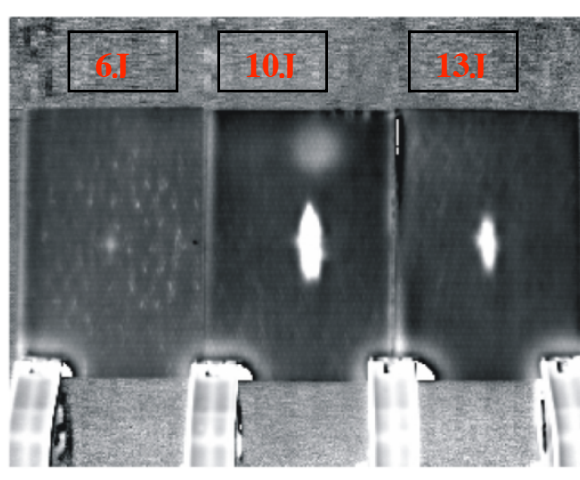

c)

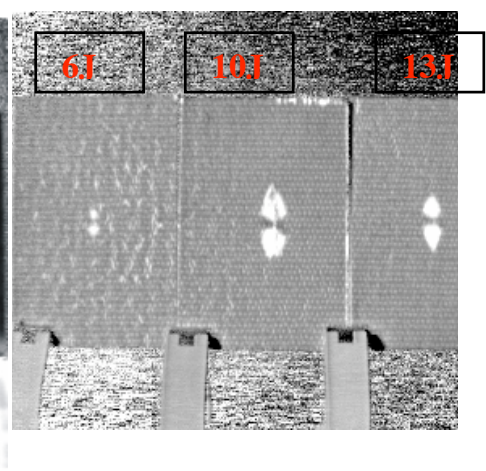

b)

Figure 20: a) phase image of the front side at @0.05Hz; b) phase image of the rear side @ $1 \mathrm{~Hz}$; c) phase image of the rear side@0.075Hz.

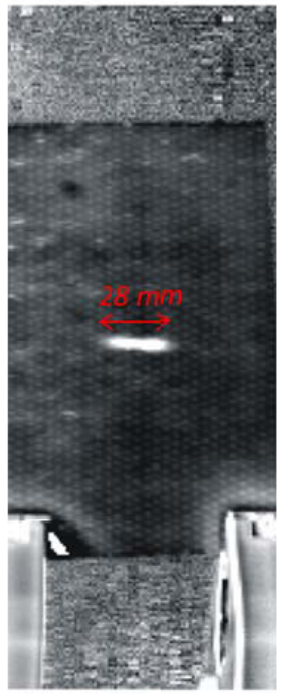

Thermography
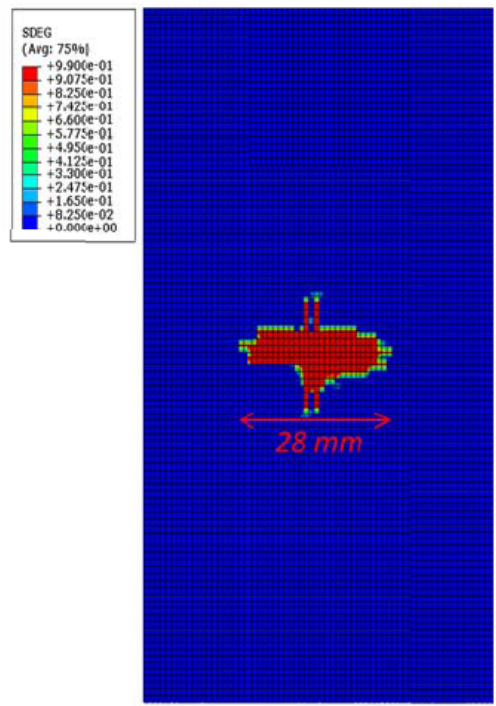

Numerical

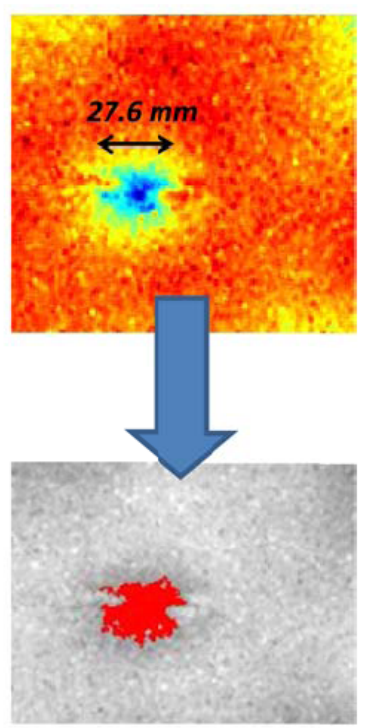

Holography

Figure 21. Comparison between NDE and numerical results [23]. Backside, U=10J.

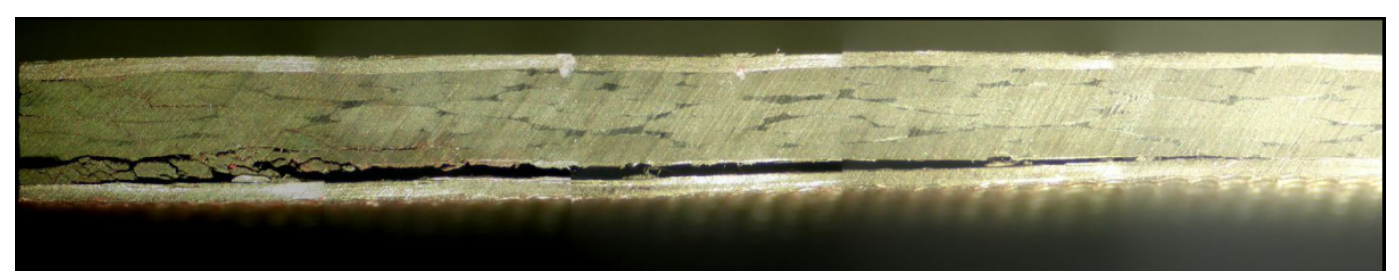

Figure 22: image of the damaged section obtained during the fractographyc test. 


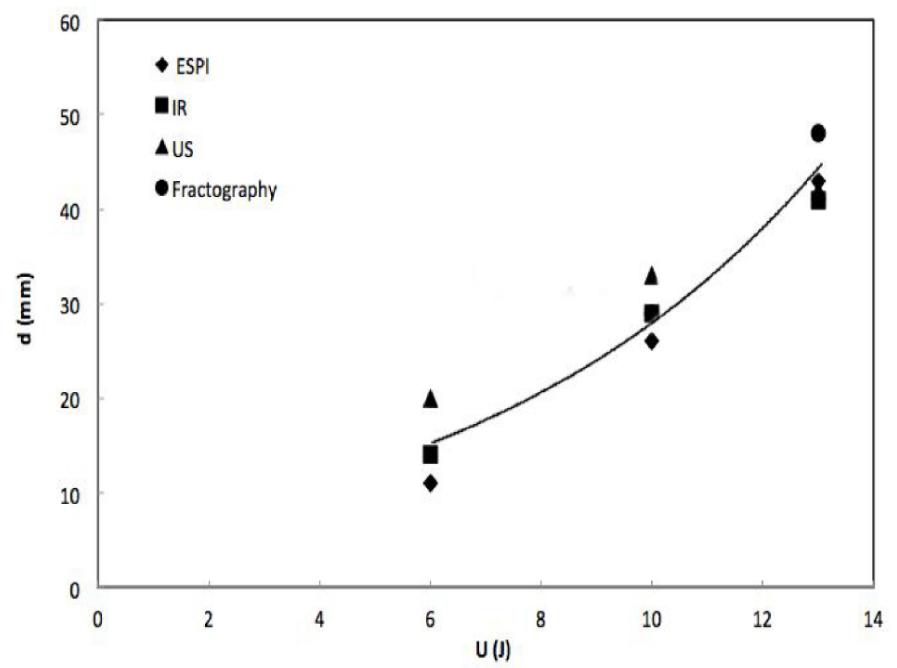

Figure 23: Maximum extension of the delamination, length d, against impact energy.

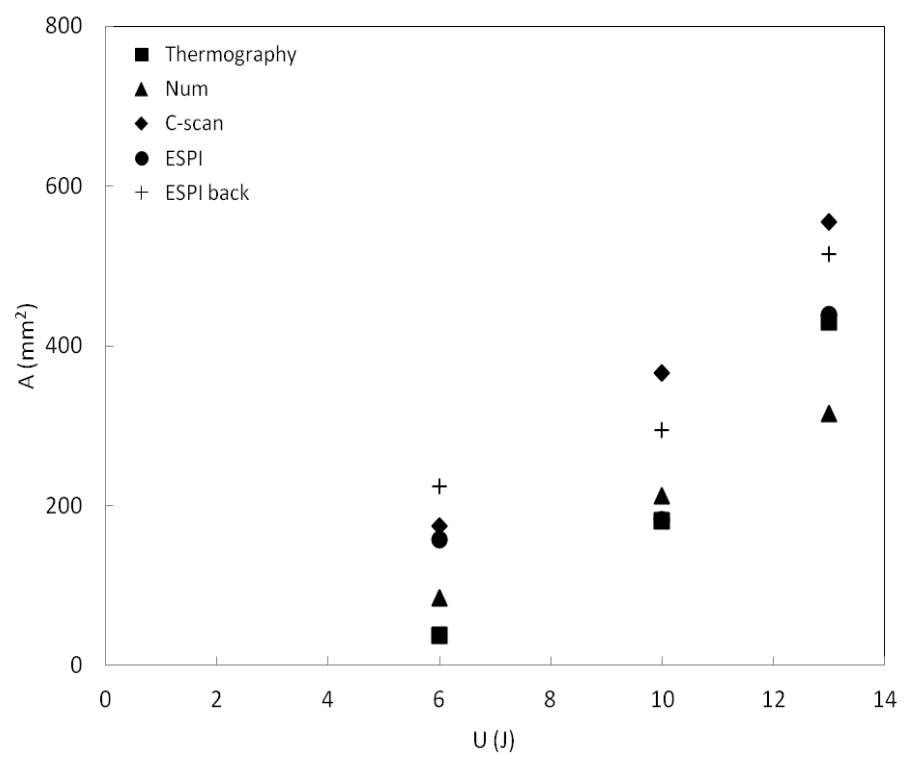

Figure 24: Delaminated area, A, against impact energy, U. 


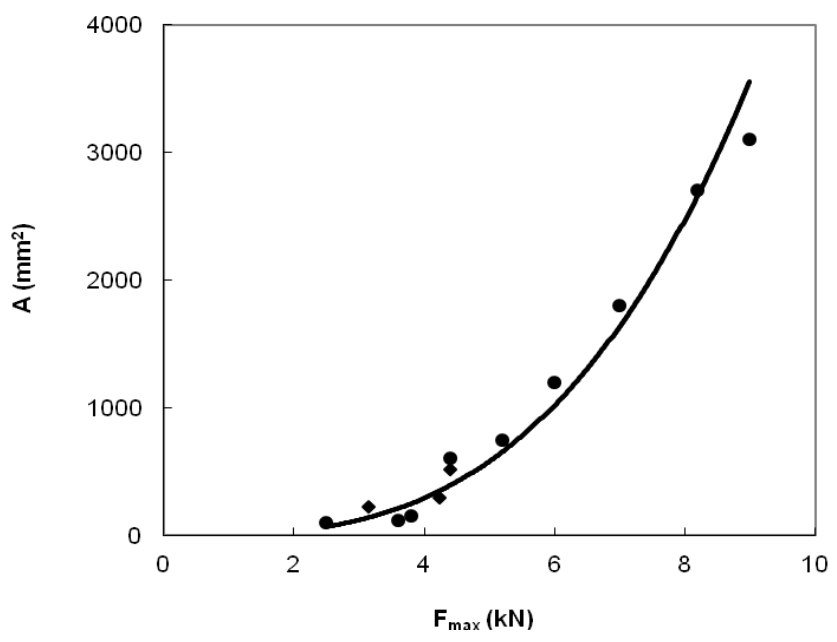

Figure 25: Delaminated area, A, vs maximum force, $\mathrm{F}_{\max }$. Rhombus: data generated here; Circle: data from [22].

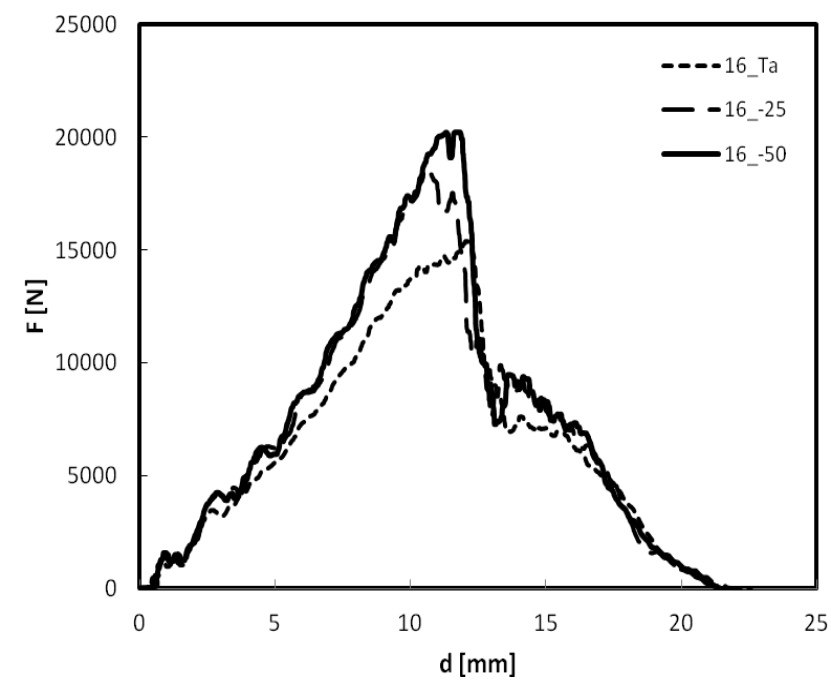

Figure 26. Force displacement curves at penetration, $\mathrm{n}=16$. 


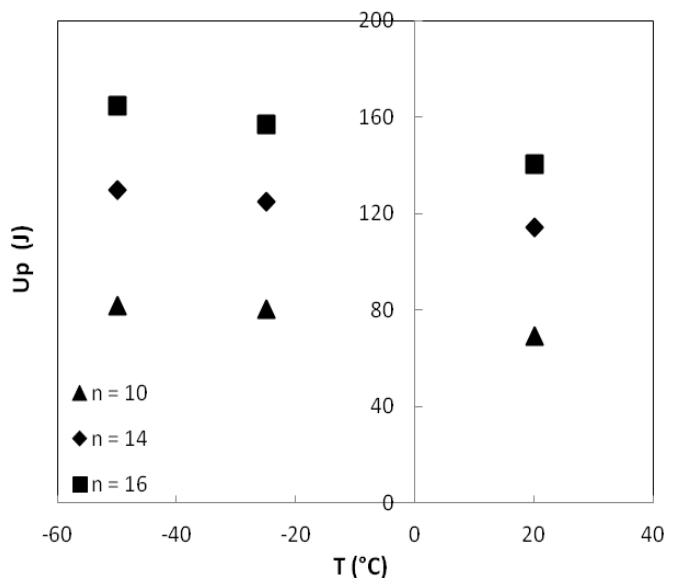

Figure 27. Penetration energy, $U_{p}$, as a function of the temperature, $T$, for the different thicknesses.

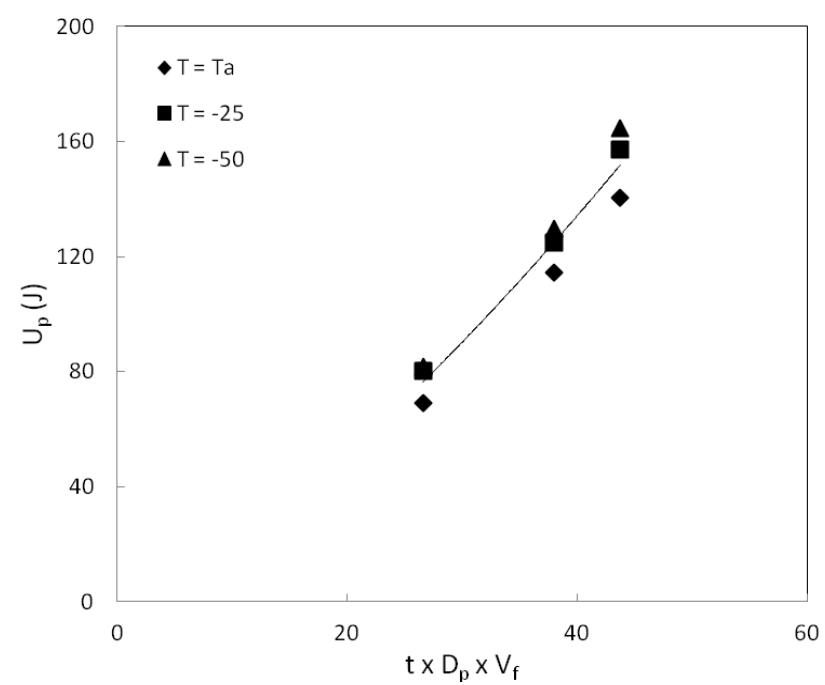

Figure 28. Penetration energy, $\mathrm{U}_{\mathrm{p}}$, against the product $\mathrm{tx}_{\mathrm{f}} \mathrm{x} \mathrm{D}_{\mathrm{p}}$, for the different temperatures. 


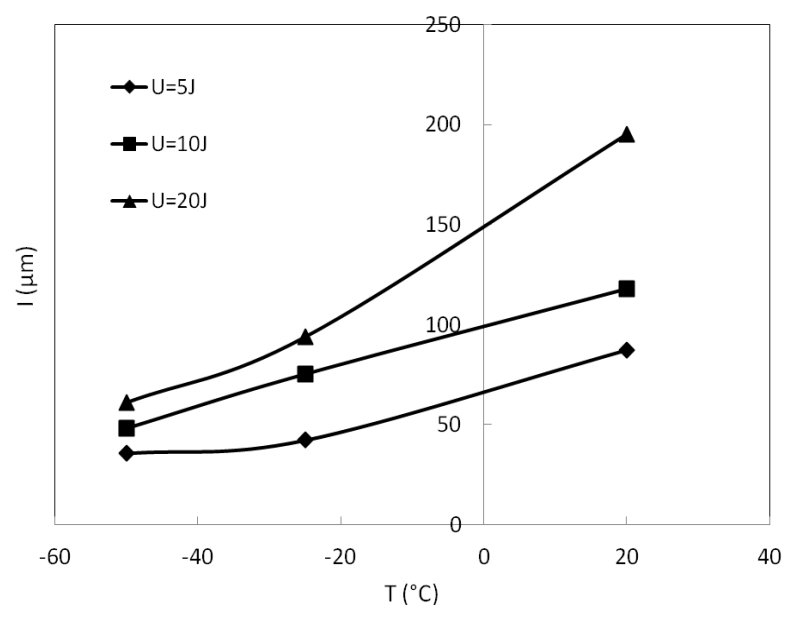

a)

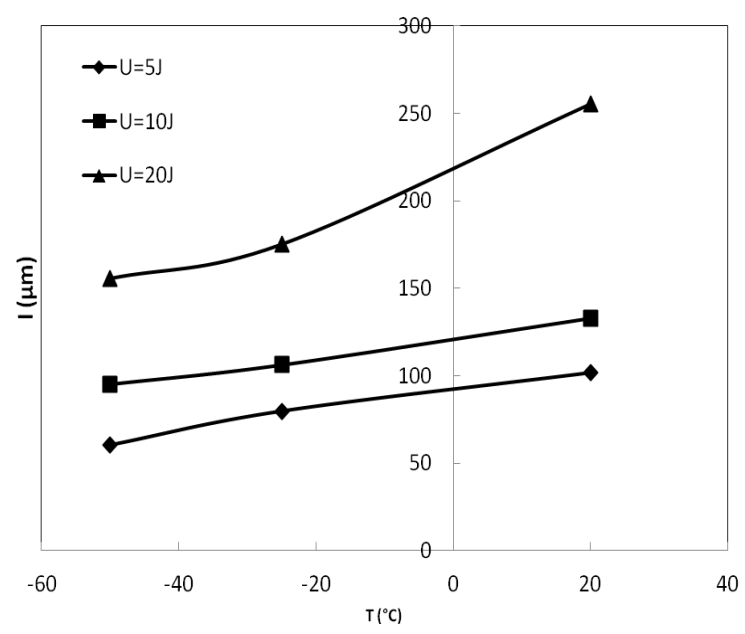

b)

Figure 29. Effect of the temperature on the indentation depth; $n=10$ (a); $n=16$ (b).

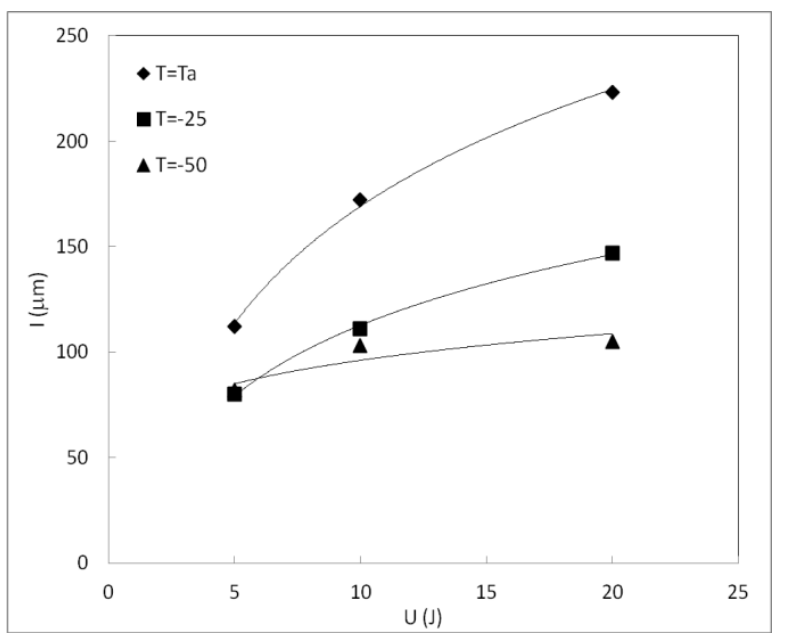

a)

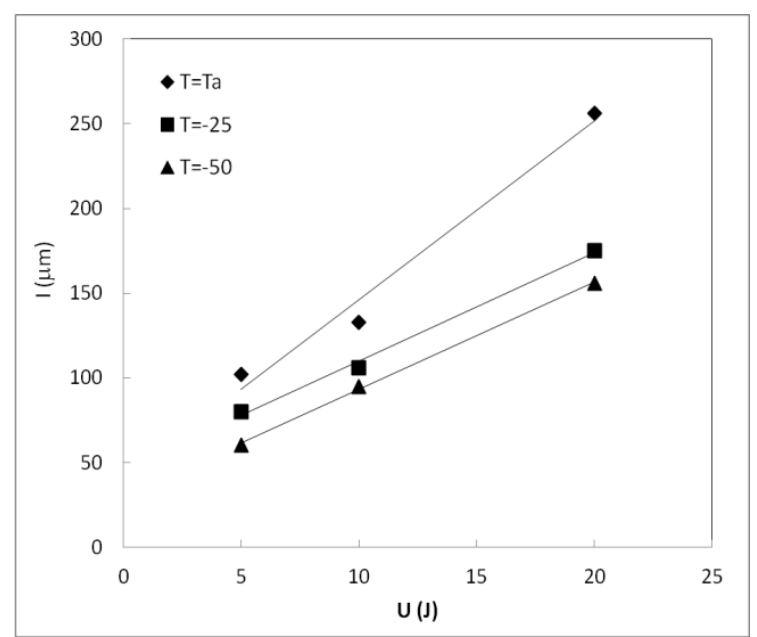

b)

Figure 30. Indentation depth, I, against impact energy, U. $n=14$ (a); n = 16 (b). 


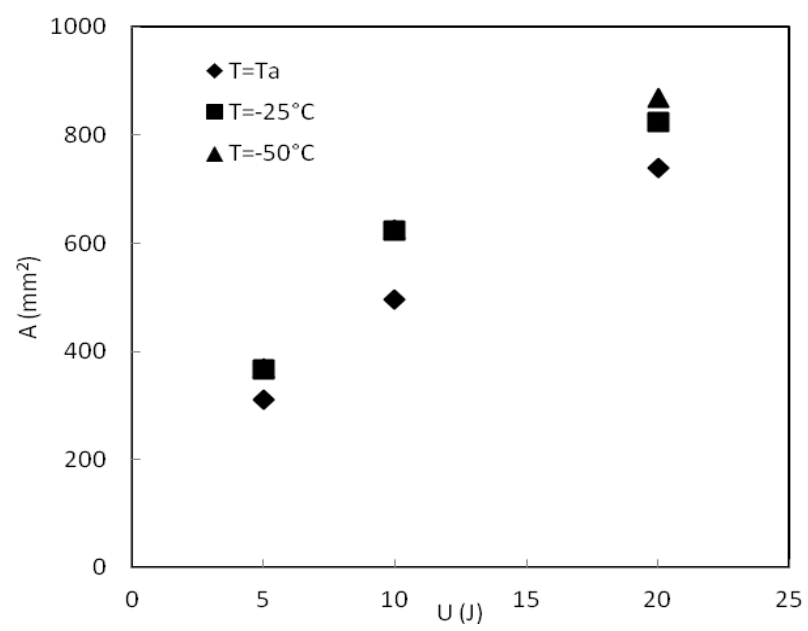

Figure 31. Delaminated area, A, vs impact energy, U. 16 layers.

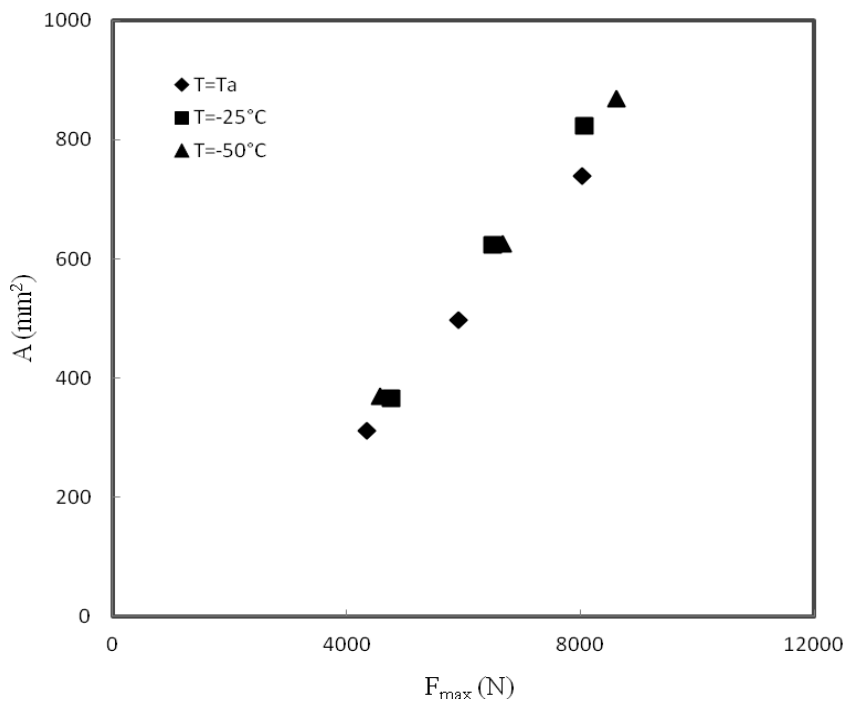

Figure 32. Delaminated area, A, vs maximum force, $\mathrm{F}_{\max } .16$ layers. 